УДК 614.841.345.6:622.276

ПРИМЕНЕНИЕ ТЕХНОЛОГИИ БЕСКОНТАКТНОГО

ЭЛЕКТРОТУШЕНИЯ ПОЖАРА НА ОБЪЕКТАХ НЕФТЕГАЗОВОЙ ПРОМЫШЛЕННОСТИ

\title{
THE USE OF THE TECHNOLOGY OF CONTACT-FREE ELECTRIC DESTRUCTION OF FIRE ON THE OIL AND GAS INDUSTRY
} FACILITIES

\author{
Т.В. Васильева, Ф.Ш. Хафизов, А.В. Пермяков, \\ И.Ф. Хафизов, И.К. Бакиров
}

Уфимский государственный нефтяной технический университет, г. Уфа, Российская Федерация

\author{
Tatyana V. Vasilyeva, Fanil Sh. Khafizov, Arseniy V. Permyakov, \\ Ildar F. Khafizov, Irek K. Bakirov
Ufa State Petroleum Technological University, Ufa, Russian Federation
e-mail: tatulik_vasileva@mail.ru

Аннотация. Пожары на объектах нефтегазового комплекса имеют большие масштабы и причиняют огромный ущерб не только производству, но и населению. Применяемые средства тушения пожаров (вода, пена и т.д.) не всегда позволяют эффективно бороться с пожарами, особенно с теми, которые имеют большую площадь горения и большую интенсивность. Чтобы решить данную проблему, необходимо создавать принципиально новые технологии тушения пожаров.

Все новое вначале парадоксально и необычно для нас, но потом мы быстро привыкаем к нему и начинаем использовать его в повседневной жизни. Так было уже не раз в истории современной цивилизации - так 
познакомились люди с автомобилем и с самолетом, с видеокамерой и телевидением, с мобильным телефоном и с компьютером и т.д.

Поэтому становится актуальным вопрос по изучению нового метода и устройств бесконтактного тушения пожаров с помощью электричества без воды.

В данной работе рассмотрена новая технология тушения пожара, основанная на применении высоковольтного электрического напряжения постоянного тока, воздействующего на пламя. Представлены теоретические основы природы тушения пожара электричеством, а также различные вариации устройств бесконтактного электротушения очага возгорания, которые можно применять при тушении пожаров на нефтегазовых объектах. Выделены основные результаты испытаний и преимущества новой технологии тушения пожара.

Abstract. Fires at oil and gas facilities are large and cause enormous damage not only to production, but also to the population. Applied means for extinguishing fire (by water, foam, etc.) do not always allow to fight effectively with fires, especially with those that have a large burning area and greater intensity. To solve this problem, it is necessary to create fundamentally new fire extinguishing technologies.

Everything new is at first paradoxical and unusual for us, but then we quickly get used to it and begin to use it in everyday life. This has happened more than once in the history of modern civilization - so people got acquainted with a car and with an airplane, with a video camera and television, with a mobile phone and with a computer, etc.

Therefore, it becomes relevant to study the new method and devices for contact-free electric destruction of fire by electricity - without water.

In this paper, there is considered a new fire extinguishing technology based on the use of high-voltage direct current voltage acting on a flame. There are presented the theoretical basis of the nature of extinguishing a fire with electricity, as well as different variations of devices for contactless electrical 
extinguishing of the fire source, which can be used to extinguish fires at oil and gas facilities. The main results of the tests and the advantages of the new fire extinguishing technology are highlighted.

Ключевые слова: технология тушения электричеством, пожарная безопасность нефтегазовой промышленности, бесконтактное тушение пожара, предотвращение возгорания, электротушение, электрическое поле

Key words: technology of electric destruction of fire, fire safety of the oil and gas industry, contact-free fire fighting, fire prevention, electric fire extinguishing, electric field

Пожары причиняют большой материальный и моральный ущерб цивилизации и считаются пока нерешенной проблемой. Обеспечение пожарной безопасности на объектах нефтегазовой промышленности является одной из приоритетных задач страны, так как эти объекты являются значимыми элементами экономики страны. К сожалению, большинство ныне существующих методов и технологий тушения пожаров на производственных объектах, в частности на объектах нефтегазовой отрасли, имеют низкую эффективность.

Для решения данной проблемы появляется потребность в создании совершенно новой технологии для ликвидации пожаров.

Уже более 20 лет назад в России был изобретен абсолютно новый эффективный метод тушения пожаров с помощью высоковольтного электричества профессором В.Д. Дудышевым [1]. Новый способ ликвидации пожара был запатентован в 1988 году [2], но до сих пор, к сожалению, не получил широкого применения, хотя имеет массу положительных особенностей.

Метод основан на создании в зоне пламени высоковольтного электрического напряжения постоянного тока. Напряженность выбирают исходя из типа пламени и его интенсивности в пределах 2-25 кВ/см [3]. 
Цель изобретения - увеличение качества и скорости тушения пожара и обеспечение предотвращения возгорания ценных объектов.

Физическая сущность метода электрического тушения заключается в том, что любое пламя насыщенно ионами. Поэтому оно может сдвигаться к одному из разноименных высоковольтных потенциалов внешнего электрического напряжения постоянного тока. За счет этого удается справиться с тушением пламени.

Практическое применение метода электрического тушения и устройств электротушения не представляет затруднений. К очагу возгорания подносят один или несколько высоковольтных жаростойких электродов, прикрепленных к источнику высоковольтного напряжения. Выбор предельных значений напряженности постоянного тока обеспечивает правильное разрушение цепных реакций горения, с помощью чего пламя быстро затухает. В большинстве случаев для тушения очага возгорания многих распространенных веществ достаточно напряженности поля от 1 до 5 кВ/см [4].

Устройства, основанные на технологии В.Д Дудышева, различаются в части конструктивного исполнения за счет различных строений электродов и их схем соединения с выходами высоковольтного электрического преобразователя напряжения.

Устройства могут быть как стационарными, так и мобильными. Одним из самых простых вариантов мобильного устройства является ранец, внутри которого размещены: источник постоянного тока, преобразователь высокого напряжения, высоковольтный конденсатор, телескопическая штанга из жаростойкого диэлектрика, оснащенная высоковольтным кабелем и креплением для активного элемента (выполнен в виде складного металлического каркаса с натянутой на нем металлической сеткой из жаропрочного сплава) [1].

Другой вариант мобильного устройства может быть полезен как при тушении пожара на территории нефтегазового комплекса, так и при 
тушении лесных пожаров. Для его реализации необходимо мобильное средство, например вертолет или автомашина высокой проходимости [5]. В техническом средстве размещают регулируемый источник высоковольтного напряжения, к которому присоединены гасящие электроды. Эти электроды закрепляются на выдвижные телескопические мачты с помощью электроизоляторов.

Также существует версия мобильного устройства, предназначенного для ограждения сооружений и установок объектов нефтегазовой промышленности и других объектов. Устройство электрополевого ограждения представляет собой подвижную систему электродов, которая с помощью специального катапультирующего пневмонического устройства мгновенно сосредотачивается по периметру очага возгорания. После развертывания электродов на них подается высокое напряжение и за счет этого быстро подавляется горение, пламя полностью затухает и устраняется дым [6]. Эффективность достигается в том случае, если площадь охвата электрополевым ограждением будет больше площади и длины фронта огня [5].

Существует версия стационарной установки тушения электричеством, которую можно использовать в качестве предотвращения возгорания и профилактики пожара особо пожароопасных или ценных объектов, таких как объекты нефтегазовой отрасли, в частности на буровых установках, на оборудованиях подготовки нефти, на газораспределительных установках, на аппаратах переработки нефти и газа и др. [7]. В этом случае для защиты охраняемого объекта вокруг него заранее устанавливается ограда из систем электродов, подсоединенных к источнику электрического поля и датчиков обнаружения возгорания, от которых поступает команда на электроды о подаче электрического поля. Воздействие электрического поля осложняет условие процесса горения за счет экстракции из потенциального очага возгорания электронов и электрически заряженных 
радикалов. В результате возгорание пламени в потенциальном очаге возгорания вещества становится невозможным [4].

В ходе многочисленных испытаний доказано [1-4], что тушение электрическим полем безопасно для людей. Ликвидацию пожаров можно обеспечить с большой скоростью на небольшом расстоянии от очага возгорания. Быстродействие увеличивается за счет увеличения напряженности постоянного тока. Данная электротехнология не причиняет большого вреда объектам защиты, как это обычно делают классические устройства пожаротушения, применяющие углекислотную пену. Также доказано, что метод эффективнее в том случае, когда площадь гасящего электрода такая же, как и площадь проекции горения в этой же плоскости.

\section{Выводы}

Новую технологию пожаротушения можно использовать в качестве эффективного противопожарного средства, подавляющего процесс горения и обеспечивающего предотвращение возгорания ценных объектов.

Несомненным плюсом этой технологии является то, что устройства электротушения не нуждаются в подзарядке огнетушащими средствами и очень просты в реализации.

Вышеперечисленные результаты исследований раскрывают преимущества электротехнологии и тем самым побуждают к предложениям по внедрению ее в промышленность и по распространению еe на уязвимых пожароопасных объектах для эффективного бесконтактного тушения пожаров и предотвращения их возгорания, в частности на объектах нефтегазовой промышленности.

Применение технологии бесконтактного электротушения пожара особенно важно для объектов нефтегазовой отрасли, так как они располагаются в местах, удаленных от источников воды. А новая технология позволяет проводить эффективное тушение без применения воды, используя лишь источник высоковольтного напряжения. 
Электрополевое ограждение поможет быстро потушить установку, на которой возник пожар, а также обеспечить защиту соседним установкам, что немало важно для обеспечения непрерывной работы. Тем самым применение новой технологии поможет обеспечить своевременное тушение без отрыва от технологических процессов и при минимальных затратах.

\section{Список используемых источников}

1. Дудышев В.Д. Новая электрическая технология бесконтактного тушения пламени и предотвращения его возгорания // Новые технологии. 2002. № 9. C. 171-173.

2. Пат. 69754 РФ, МПК А 62 С 37/00. Устройство электрического пожаротушения / В.Д. Дудышев, Л.В. Афанасьева. 2008.

3. Подрезов И.А., Ставицкий А.В. Тушение открытого огня с помощью электрического поля // Сборник материалов LI Международной студенческой научно-практической конференции. Уфа, 2017. С. 149-152.

4. Дудышев В.Д. Новая технология бесконтактного тушения и предотвращения пожаров. // Экология и промышленность России. 2003. № 12. C. 184-186.

5. Новая электрическая технология бесконтактного тушения пожаров. URL: $\quad$ http://www.ntpo.com/izobreteniya-dudysheva/7575-novayaelektricheskaya-tehnologiya-beskontaktnogo-tusheniya-pozharov.html (дата обращения: 10.12.2018).

6. Хафизов Ф.Ш., Пермяков А.В., Хафизов И.Ф., Краснов А.В., Пережогин Д.Ю., Еникеева Э.Д. Исследование влияния электромагнитного поля высокой напряженности на пламя // Проблемы сбора, подготовки и транспорта нефти и нефтепродуктов. 2016. Вып. 2 (104). С. 105-110.

7. Хафизов Ф.Ш., Бакиров И.К. Пожарные риски: кто ответит за пожар? // Пожаровзрывобезопасность. 2010. Т. 19. №9. С. 2-4. 


\section{References}

1. Dudyshev V.D. Novaya elektricheskaya tekhnologiya beskontaktnogo tusheniya plameni i predotvrashcheniya ego vozgoraniya [New Electrical Technology for Contactless Extinguishing the Flame and Preventing its Ignition]. Novye tekhnologii - New Technologies, 2002, No. 9, pp. 171-173. [in Russian].

2. Dudyshev V.D., Afanasyev L.V. Ustroistvo elektricheskogo pozharotusheniya [The Device of Electric Fire Extinguishing]. Patent RF, No. 69754, 2008. [in Russian].

3. Podrezov I.A., Stavitsky A.V. Tushenie otkrytogo ognya s pomoshch'yu elektricheskogo polya [Extinguishing an Open Flame Using an Electric Field] Sbornik materialov LI Mezhdunarodnoi studencheskoi nauchno-prakticheskoi konferentsii [Proceedings of the LI International Student Scientific Practical Conference]. Ufa, 2017, pp. 149-152. [in Russian].

4. Dudyshev V.D. Novaya tekhnologiya beskontaktnogo tusheniya i predotvrashcheniya pozharov [New Technology for Contactless Extinguishing and Fire Prevention]. Ekologiya i promyshlennost' Rossii - Ecology and Industry of Russia, 2003, No. 12, pp. 184-186. [in Russian].

5. Novaya elektricheskaya tekhnologiya beskontaktnogo tusheniya pozharov [New Electric Technology of Contactless Fire Extinguishing]. Available at: http://www.ntpo.com/izobreteniya-dudysheva/7575-novaya-elektricheskayatehnologiya-beskontaktnogo-tusheniya-pozharov.html (accessed 10.12.2018). [in Russian].

6. Khafizov F.Sh., Permyakov A.V., Khafizov I.F., Krasnov A.V., Perezhogin D.Yu., Enikeyeva E.D. Issledovaniye vliyaniya elektromagnitnogo polya vysokoy napryazhennosti na plamya [Study of the Influence of HighIntensity Electromagnetic Field on the Flame]. Problemy sbora, podgotovki $i$ transporta nefti $i$ nefteproduktov - Problems of Gathering, Treatment and Transportation of Oil and Oil Products, 2016, Issue 2 (104), pp. 105-110. [in Russian]. 
7. Khafizov F.Sh., Bakirov I.K. Pozharnye riski: kto otvetit za pozhar? [Fire Risks: Who will be Responsible for the Fire?]. Pozharovzryvobezopasnost' Fire and Explosion Safety, 2010, Vol. 19, No. 9, pp. 2-4. [in Russian].

\section{Сведения об авторах}

\section{About the authors}

Васильева Татьяна Викторовна, магистрант кафедры «Пожарная и промышленная безопасность», УГНТУ, г. Уфа, Российская Федерация

Tatyana V. Vasilyeva, Undergraduate Student of Fire and Industrial Safety Department, USPTU, Ufa, Russian Federation

e-mail: tatulik_vasileva@mail.ru

Хафизов Фаниль Шамильевич, доктор технических наук, профессор, заведующий кафедрой «Пожарная и промышленная безопасность», УГНТУ, г. Уфа, Российская Федерация

Fanil Sh. Khafizov, Doctor of Engineering Sciences, Professor, Head of Fire and Industrial Safety Department, USPTU, Ufa, Russian Federation

e-mail:pkpb@mail.ru

Пермяков Арсений Владимирович, преподаватель кафедры «Пожарная и промышленная безопасность», УГНТУ, г. Уфа, Российская Федерация

Arseniy V. Permyakov, Lecturer of Fire and Industrial Safety Department, USPTU, Ufa, Russian Federation

e-mail: senya2512@yandex.ru

Хафизов Ильдар Фанильевич, доктор технических наук, профессор кафедры «Пожарная и промышленная безопасность», УГНТУ, г. Уфа, Российская Федерация

Ildar F. Khafizov, Doctor of Engineering Sciences, Professor of Fire and Industrial Safety Department, USPTU, Ufa, Russian Federation

e-mail: ildar.hafizov@mail.ru 
Бакиров Ирек Климович, кандидат технических наук, доцент кафедры «Пожарная и промышленная безопасность», УГНТУ, г. Уфа, Российская Федерация

Irek K. Bakirov, Candidate of Engineering Sciences, Assistant Professor of Fire and Industrial Safety Department, USPTU, Ufa, Russian Federation e-mail: bakirovirek@bk.ru 